treatment of septic peritonitis, namely, raising the head and trunk of the patient to such a level that the effusion in the peritoneum shall sink down into its least dangerous region within the pelvis. After performing laparotomy, and adopting the usual surgical measures for removing the cause of the inflammation, he props up the patient's head and trunk, and inserts drainage tubes into the pelvis, through which the fluid is repeatedly removed as it flows down into that region. The result seems to have been admirable. He relates nine successive cases of diffuse septic peritonitis treated by the combined methods of elevated posture and drainage, all of which resulted in recovery. He has not included among these several cases in which a spreading peritonitis existed about a focus of infection, as shown by a decided redness of the coils of intestine in the neighbourhood, and which were apparently arrested by the elevated head and trunk position, although in these also the convalescence was rapid, and the condition seemed to be more comfortable than is usual during the first few hours after operation. For the purpose of comparison, Dr. Fowler takes an equal number of cases of diffuse septic peritonitis occurring in his hospital practice which were subjected to the same measures of treatment, with the exception of the elevated head and trunk posture. Of these cases four recovered and five died. The record of nine consecutive cases of diffuse septic peritonitis terminating in recovery is, he says, extraordinary, not to say startling, and whatever doubt may still cling about the questions of eventration, or the use of peroxide of hydrogen, or the flushing of the peritoneum with large quantities of decinormal saline, he has no hesitation in speaking with confidence upon two points in the treatment of septic peritonitis, namely, the employment of the elevated head and trunk position, and drainage of the pelvic cavity by means of well-placed and protected glass drains. The angle at which the patients have been placed has varied somewhat, but the elevation of the bed from the horizontal has been generally from twelve to fifteen inches.

1 Med, Rec., April 14.

\section{THE NEGRO.}

Events in South Africa tend to give prominence to the negro question, which is not unlikely to give rise to serious differences of opinion when the task of settling affairs in that part of the world comes to be undertaken. American experience does not seem to be an altogether happy one, especially in regard to the witheracy of the race under the influence of civilisation without control. Dr. Paul B. Barringer, of the Unithersity of Virginia, who recently gave an address on and subject before the Tri-State Association of Virginia propen Carolinas, after referring to the cannibalistic presentities of the West Coast African negro of the "Thir day, speaks of the American negro as follows: from th. five years have passed since the negro changed every the condition of a slave to that of a freed-man. In unbit part the south, it is the opinion of every man of worse than mind that the second generation is infinitely South, except first. . . . The young negro of the tional except where descended from parents of excephereditary focter and worth, is reverting through to the fact forces to savagery. . . . Everything points the fact that the phylogeny of the negro is carrying him back to barbarism; that the temporary elevation produced by the discipline of slavery is not being maintained by the efforts we have made at commonschool education in the hands of his own race, and that we must at once, if we would save the negro and the South, try something else." The Medical Record, in reporting the above remarks, adds that it has many times called attention to the physical deterioration of the coloured race on the American continent, clearly owing to the insanitary conditions in which its members live. The matter is, it says, of the most serious importance, and yearly assumes a more ominous aspect.

\section{A MINING ACCIDENT.}

A VERY extraordinary occurrence is reported in the British Medical Journal by Mr. Ernest V. Eames. It happened in descending a colliery shaft. A cage in which 18 men were being lowered into the pit, 200 yards deep, ran away - that is, the engineman lost control of his engine when the cage was about 60 yards from the bottom. Consequently the men were precipitated down the shaft at a terrific speed until the cage was brought to a sudden stand by impact with the planks placed across the "sump hole" at the bottom. The men during their descent are said habitually to stand in a rather stooping position, with the legs straight and the head and shoulders rather bent. Now of the 18 men five suffered dislocation of the knee, all in the same direction, the head of the tibia and the fibula being carried forwards and shot up on the anterior surface of the femur. In three of the cases the skin was split across the back of the joint, but without opening the joint cavity, and in one there was an oblique fracture of the tibia as well as dislocation of the knee. In all the cases but one a good result was obtained, the men being at work under five months from the date of the accident, with practically sound knees, of the same appearance as before, and of equal usefulness. The case in which a bad result followed was the one which was complicated with fracture of the tibia. In this case the man remains with a flat joint, and he also has paralysis of the extensor muscles of the foot. The form of dislocation here met with is sufficiently uncommon, but its occurrence in five men at the same time seems quite unique.

\section{SPONGE COUNTING.}

Dr. Wengebauer, of Warsaw, has recently done a good piece of work in collecting a long series of cases in which, in closing the wound after laparotomy, sponges and instruments of one kind and another have been accidentally left in the abdomen. He has got together 101 cases, in 38 of which the foreign body was only found at the necropsy. Among the more curious of the bodies left in the abdomen was a signet ring. This was removed from Douglas's pouch by operation through the vagina two years after a laparotomy. That a surgeon should operate with rings on his fingers is a strange commentary on all that we hear about modern antiseptic precautions. It is rather interesting to note that the known liability of sponges, forceps, and other things to be lost in the abdomen leads sometimes to a sort of scare on the subject. The idea is somehow suggested that something has been left; the operator going over in his mind every step of the operation is unable to shake off the feeling that it is so; and he therefore reopens the wound but finds nothing. This occurred twice. The importance of a careful count of both instruments and sponges cannot be exaggerated. 